nas putrefaciens bacter emia. Rev Infect Dis 1989; 11:97104.

9. Dan M, Gutman R, Biro A. Peritonitis caused by $P$ seudomonas putrefaciens in patients undergoing continuous ambulatory peritoneal dialysis. Clin Infect Dis 1992; 14:359-60.

10. Paul K, DePK, Bhattacharya S. Comparative efficacy of fluoroquinolones, aminoglycosides, ureidopenicillins \& newer cephalosporins against $P$ seudomonas spe cies.Indian J Med Res 1992;95:136-8.

\section{Shock hipovolémico por fístula aortoentérica}

Una comunicación directa entre la aorta (o una de sus ramas) y el tracto gastrointestinal, conocida como fístula aortoentéricas, es una causa rara de hemorragia gastrointestinal. La etiología usual suele ser la erosión producida por un aneurisma arteriosclerótico en el duodeno, pero se describen otras causas y variedades, así como otras localizaciones. La presentación clínica habitual suele ser el sangrado intermitente poco importante, que conduce a una situación de hipovolemia en el plazo de horas a días, siendo el dolor o la presencia de una masa pulsátil un hallazgo frecuente. La endoscopia, la arteriogr afía, los ultr asonidos o incluso el TAC se suelen utilizar para el diagnóstico en estos pacientes. Las fístulas aortoentéricas primarias se suelen descubrir durante la realización de una laparotomía, sin un diagnóstico preope ratorio preciso (1). Presentamos aquí el caso de un paciente con un cuadro de rectorragia masiva secundaria a fístula iliaco-entérica.

Paciente de 66 años de edad, con antecedentes per sonales de ulcus péptico y portador de un filtro en cava por cuadro de trombosis venosa profunda en miembro inferior derecho, que ingresa en el hospital para estudio de un cuadro de 48 horas de evolución de alteración en el ritmo intestinal y dolor continuo en hipogastrio y flancos de características opresivas. Toda la analítica era normal.

Para descartar patología relacionada con el filtro de cava que portaba el paciente, se realiza en primer lugar un TAC abdominal que muestra un aneurisma de aorta abdominal suprarrenal sin compromiso de la luz, sin otra patología asociada. Encontrándose a la espera de nuevas pruebas complementarias, a las 24 horas de su ingreso, el paciente sufre episodio súbito de rectorragia de aproximadamente 1 litro de sangre roja rutilante, inician- do cuadro de inestabilidad hemodinámica (presión arterial de 50/30 mmH g, frecuencia car diaca de 120 lpm, y claros signos de hipoperfusión periférica), ingresando en la unidad de cuidados intensivos. A su ingreso es intubado, conectado a ventilación mecánica y tras canalizar vías centrales, se inicia perfusión de fluidos (derivados sanguíneos, cristaloides y coloides). En la analítica rutinaria de ingreso sólo destacaba la presencia de un sodio plasmático de $157 \mathrm{meq} / \mathrm{ml}$, con una hemoglobina de $7,2 \mathrm{~g} / \mathrm{dl}, \mathrm{H}$ cto del $21 \%, 18.600$ leucocitos, 199.000 plaquetas, actividad de protrombina del $45 \%$ y TTPA de 48 segundos (sobre un control máximo de 38). En la gasometría arterial, con fracción inspiratoria de oxigeno de 1: $7,36 / 67 / 360 / 38 / 99 \%$, tras el aporte de 250 meq de bicarbonato un molar.

Tras su estabilización hemodinámica, se solicita endoscopia oral urgente que no encuentra alteración patológica alguna, realizándose a continuación arteriografía de ramas intestinales y cavogr afía que resultan ser no concluyentes al no mostrar extravasación de contraste. En esta situación, la exploración abdominal comienza a mostrar claros signos de abdomen agudo. En la laparotomía se objetiva una neoformación, identificada posteriormente por anatomía patológica como un adenocarcinoma bien diferenciado de sigma-recto, con afectación de los vasos ilíacos (una fistulización intestinal) y peritonitisfecaloidea, procediéndose a la resección de toda la zona con realización de ano ilíaco permanente según técnica de H artmann.

El paciente reingresa en la unidad hemodinámicamente estable, tras habérsele transfundido un total de 13 bolsas de sangre entre el periodo de la resucitación y el quirófano. En su evolución es extubado sin incidencias, requiriendo el empleo de dopamina y aporte de volumen por hipotensión y oliguria en las 48 horas posteriores a la intervención. Se inició tratamiento antibiótico empírico con clindamicina, tobramicina, y una cefalosporina como tratamiento de la peritonitis. Fue dado de alta en nuestro servicio a los 5 días de su ingreso, siendo remitido a su casa 14 días más tarde sin haber presentado otro episodio de sangrado.

En el caso de una hemorragia digestiva baja la sangre expulsada puede presentar las características de rectorragia o hematoquecia, y eventualmente, caso de proceder de segmentos algo más altos, de melena. La hemorragia aguda suele incidir con mayor frecuencia por encima de los 60 años, y su frecuencia es menor que en el caso de la hemor ragia digestiva alta.
El estudio de estas hemorragias cobra un inter és especial pues en los últimos 20 años han cambiado los métodos exploratorios y la mentalidad terapéutica en gran parte. Al arsenal diagnóstico se han incorporado la angiografía selectiva, la fibrocolonoscopia y los barridos con radioisótopos, gracias a los cuales se puede determinar con exactitud el punto sangrante. En lo concer niente a los tratamientos, se han mejorado con la incorporación de infusiones intraarteriales de vasoconstrictores, embolización a través de sondas, extirpación endoscópica y electrocoagulación endoscópica. Previamente a la existencia de los mismos, la mayoría de las hemor ragias digestivas agudas eran atribuidas a la existencia de diverticulosis. La radiología convencional y la endoscopia tenía poca sensibilidad diagnóstica en la hemorragia digestiva baja originada en segmentos proximales a la región rectosigmoidea. En esta situación la angiografía tiene una utilidad mucho mayor que en la hemorragia digestiva alta, en la que la endoscopia sí tiene un alto porcentaje de acier tos diagnósticos. En la hemorragia con un débito superior a $0,5 \mathrm{ml} / \mathrm{min}$ la arteriografía mesentérica suele localizar el punto sangrante mediante la visualización de contraste extravasado, teniendo un gran valor diagnóstico en los pacientes con hemorragia secundaria a anomalías vascular es (angiodisplasias, hemangiomas, y como en nuestro caso, fístulas aortoentéricas). Los estudios isotópicos son útiles para detectar débitos incluso de $0,1 \mathrm{ml} / \mathrm{min}$, excepto en el caso de que el sangrado tenga su origen en el ángulo hepático pues se verá artefactado por la captación del parénquima hepático.

L as fístulas aor toentéricas primarias son una complicación poco frecuente pero severa resultante de la erosión de los aneurismas abdominales o de neoplasias. Según estudios, sólo el $31 \%$ de las mismas se puede considerar primaria pues el $69 \%$ restante son secundarias a la reconstrucción de injertos vasculares aórticos mediante prótesis (2). EI diagnóstico temprano y el tratamiento eficaz son cruciales para la supervivencia. Generalmente el diagnóstico se lleva a cabo intraoperativamente, a causa de lo poco específico de su clínica (hemor ragia digestiva, masa abdominal o dolor), que lleva generalmente al paciente al campo de lo crítico y debiendo requerir una decisión quirúr gica rápida y no el empleo para su diagnóstico de complicadas técnicas. La endoscopia y la radiología para el diagnóstico de las mismas puede ser muy útiles, pero la normalidad en las mismas no lo excluye, estando indicada la lapar otomía exploradora en los pacien- 
tes con sangrado gastrointestinal masivo 0 en quienes el resultado de ellas fue normal. De todas formas, a pesar de un rápido reconocimiento de la patología esta patología conlleva una alta mortalidad, fundamentalmente cuando conlleva un estado de shock, pero una correcta técnica quirúrgica y una prolongada medicación antibiótica postoperatoria minimizan esta situaciór (3).

Cuando existe un sangrado importante, aunque no masivo, no están indicadas las exploraciones que demoren el diagnóstico, y debe procederse a la mayor brevedad a la arteriografía, que permitirá la localización del punto sangrante, para orientación del cirujano, y ocasionalmente la realización de cier tas medidas terapéuticas, como pudieran ser la realización de embolizaciones o la inyección con vasopresina. En los casos especialmente graves deberá obviarse la arteriografía para pasar directamen te a la cirugía de urgencia.

\section{A. Córdoba López, M. Robles Marcos, M. Antona D íaz, J. A. J uliá Narváez}

Unidad de Cuidados I ntensivos. H ospital Regional Universitario Infanta Cristina. Badajoz

1. Voorhoeve R, Moll FL, de Letter J A, Bast J, W ester J P, Slee PH. Primary aortoenteric fistula: report ogf eight new cases and review of the literature. Ann Vasc Surg 1996. J an tO (1)P 40-8.

2. Peck JJ, Eidmuller LR. Aortoenteric fistulas. Arch Surg. 1992 Oct. 127 (10) P 11913.

3. Ghilardi G, Longhi F, Sgroi G, Bergamaschi E, Scorza R. Primary aorto-enteric communication. Minerva Cardioangiol. 1994. May. 425) P 233-7.

\section{Paciente con infección por el VIH y acromegalia}

\section{Sr. Director:}

La hormona del crecimiento es una potente proteina anabólica que ha sido evaluada en el síndrome de caquexia asociado al VIH (1-3). Desde el punto de vista inmunológico existen evidencias de que esta hormona estimula la producción de difer entes células y citoquinas implicadas en la replicación del VIH (4).

Presentamos el caso de un paciente con infección por VIH con criterios de larga supervivencia en el que se diagnostica una acromegalia. Aunque esta asociación puede ser debida al azar, no se puede descartar un posible efecto inhibitorio sobre la replicación viral a causa de la hiperproducción endógena de hormona del crecimiento prolongada en el tiempo.

Varón de 32 años de edad, con antecedentes de adicción a drogas por vía parenteral, e infección por el VIH desde 1986; año en que se diagnostica de diabetes mellitus, a raíz de un cuadro de descompensación cetoacidótica. En esta ocasión la cifra de linfocitos CD 4 fue de 690 x 106/L. Durante el período entre 1987 hasta 1990 el paciente fue perdido de seguimiento puesto que ingresa en prisión. Desde 1990 hasta 1992, vuelve a estar en control ; objetivándose cifras de linfocitos CD4 siempre superior es a $500 \times 10^{6} / \mathrm{L}$.

En 1993 el paciente ingresa por cuadro febril y dificultad respiratoria como consecuencia de un empiema estreptocócico, que se solventa con tratamiento antibiótico y drenaje pleural. En esta ocasión el paciente refirió cambios somáticos, caracter izados por crecimiento de partes acras y deformidad facial, que se constataron en una comparación fotográfica retrospectiva.

Se solicita estudio hormonal y RMN (RMN) cerebral. La RMN mostró la existencia de un macroadenoma hipofisario con extensión supra e infraselar (Fig. 1). El nivel basal de la hormona del crecimiento (HG) fue de $43,1 \mathrm{mg} / \mathrm{L}$ (N: $0-5)$. A los 20 y 40 minutos fue de 46 y $44 \mathrm{mg} / \mathrm{L}$ respectivamente. IGF -I (Insulin Like GF I) fue de $1.600 \mathrm{ng} / \mathrm{ml}$ (N: 171-333). El estudio de los ejes adrenal, tiroideo y gonadal no mostró alter aciones; la cifra de linfocitos CD 4 fue de $510 \times 10^{6} / \mathrm{L}$ y la beta 2 microglobulina de $169 \mathrm{nmol} / \mathrm{L}$.

Se inició tratamiento con octreotido a dosis de $100 \mathrm{mg}$ subcutáneos cada 8 horas de forma indefinida así como radioterapia paliativa, hasta el año 1995 donde se abor da neur oquirúrgica-

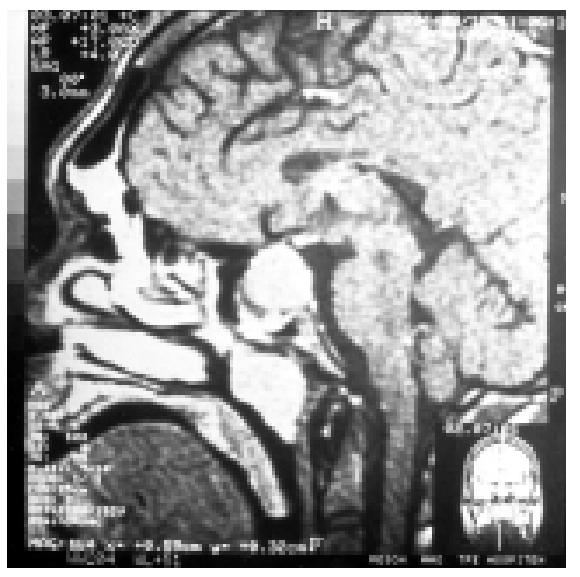

Fig. 1. mente al paciente, procediéndose a resección parcial del macroadenoma. La última cifra de linfocitos CD4 de octubre de 1997 fue de $416 \times 10^{6} / \mathrm{L}$.

La hormona del crecimiento es una potente proteína anabólica que ha sido evaluada desde el punto de vista terapéutico en varios ensayos clínicos en el síndrome caquéctico asociado a la infección VIH (1-3). En estos estudios se usaron dosis ter apéuticas a corto plazo de rhGH; obteniéndose resultados aceptables desde el punto de vista nutricional, mínimos efectos secundarios y, aparentemente ningún efecto sobre la replicación viral. Este último evento fue evaluado mediante la determinación del antígeno P -24 y el recuento de linfocitos CD4 en todos los ensayos. Los pacientes en general presentaban importante deterioro de la inmunidad celular y los periodos de tratamiento fueron inferiores a tres meses.

Desde el punto de vista inmunológico, existen evidencias a favor de que la hormona del crecimiento pueda estimular la producción de células T y monocitos, así como la producción de citoquinas como la IL-1, IL-2 y TNFalfa; factores que están implicados en la replicación del VIH in vitro (4). P or otro lado, el provirus DNA-VIH en su fragmento LTR (Long Ter minal R epeat) contiene varias secuencias consensus de citoquinas, que incluyen a un elemento palindrómico compartido por la pro-GH, y ubicado en la región NRE (N egative R egulatory Element); como sabemos la LTR está directamente implicada en la expresión precoz de los genes reguladores del VIH (5).

J. Laurence et al (6), en un modelo experimental, observaron que la rhGH incrementaba la replicación viral en células mononucleares de sangre periférica infectadas de forma aguda con el VIH. Este efecto fue observado a concentraciones farmacológicas de rhGH. Paradójicamente, en los experimientos en los que se utilizaron altas dosis de rhGH, la replicación viral revertía a concentraciones basales o sub-basales. Este efecto fue inter pretado como un efecto divergente en la producción de citoquinas y en la proliferación celular.

Obviamente en el caso que se presenta la asociación de acromegalia e infección por el VIH con criterios de larga supervivencia podría ser debida al azar, sin embargo no podemos descartar un posible efecto inhibitorio sobre la replicación viral como consecuencia de la hiperproducción de hormona del crecimiento endógena mantenida en el tiempo. 